\title{
AKTUALISASI TRADISI MEBUUG-BUUGAN SEBAGAI BENTENG BUDAYA DI DESA ADAT KEDONGANAN, KECAMATAN KUTA, KABUPATEN BADUNG
}

\author{
Oleh: \\ I Made Sudarsana \\ sudarsana@unhi.ac.id \\ Dosen Fakultas Pendidikan, UNHI Denpasar \\ Ida Ayu Gede Prayitna Dewi \\ Dosen Fakultas Pendidikan, UNHI Denpasar
}

\begin{abstract}
ABSTRAK
Keberadaan seni tradisional, kini telah menjadi citra budaya daerah dan mampu berdampak dinamis pada masyarakat. Tradisi yang berkembang, dan didasarkan pada suatu wilayah tentu melalui proses perjalanan panjang sehingga menjadi sistem kebiasaan yang dilakukan secara terus menerus. Pembentukan perspektif yang sama dan terkait dengan mitologi lokal, adalah fondasi awal bagi seorang inisiator dan genius lokal untuk merumuskan perspektifnya di ruang tradisional. Ini menunjukkan bahwa peran tradisi saat ini, dapat dijadikan barometer kekayaan yang memiliki investasi tinggi di suatu daerah. Fenomena munculnya tradisi yang telah dipinggirkan karena keberadaannya, saat ini seolah-olah akan menjadi permata bernilai tinggi dan munculnya rekonstruksi tradisi yang hilang. Khususnya di Desa Adong Kedonganan, Kecamatan Kuta, Kabupaten Badung, tradisi Mebuug - buugan telah direkonstruksi sejak 2014 lalu. Tradisi ini, yang ditinggalkan hampir 60 tahun, adalah tradisi permainan menggunakan lumpur / buug di hutan bakau. Kelanjutan tradisi ini mampu mengangkat kearifan lokal yang terkandung di dalamnya, terutama di Desa Adat Kedonganan. Banyak konten filosofis dan nilainilai sosial dapat diimplementasikan melalui media tradisional buugan Mebuug ini. Penerapan konsep Tri Hita Karana dalam tradisi Mebuug Buugan sangat relevan dengan upaya masyarakat untuk menjaga hubungan yang harmonis atau interaksi sosial masyarakat dan ekologi lingkungan alam Mangrove.
\end{abstract}

Kata Kunci: Tradisi, Aktualisasi, Mebuug-Buugan, Kearifan Lokal 


\begin{abstract}
The existence of traditional arts, has now become an image of regional culture and is able to have a dynamic impact on the community. The tradition that develops, and is grounded in an area certainly through a long journey process so that it becomes a system of habits that is carried out continuously. The formation of a similar perspective and associated with local mythology, is the initial foundation for an initiator and local genius to formulate his perspective in the traditional space. This shows that the role of tradition today, can be used as a barometer of wealth that has high investment in an area. The phenomenon of the emergence of tradition that has been marginalized for its existence, nowadays it is as if it will become a gem of high value and the emergence of the reconstruction of lost traditions. Particularly in the Adong Village of Kedonganan, Kuta District of Badung Regency, the Mebuug - buugan tradition has been reconstructed since 2014 ago. This tradition, which is left behind almost 60 years, is a game tradition using mud / buug in mangroves. The continuity of this tradition is able to elevate the local wisdom contained in it, especially in the Traditional Village of Kedonganan. Many philosophical contents and social values can be implemented through this Mebuug buugan traditional media. The application of the Tri Hita Karana concept in the Mebuug Buugan tradition is very relevant to the efforts of the community to maintain a harmonious relationship or social interaction of the people and the ecology of the natural environment of the Mangrove.
\end{abstract}

Key words: Tradition, actualization, mebuug --buugan, local wisdom

\section{PENDAHULUAN}

Tradisi dalam suatu daerah merupakan suatu kekayaan yang sangat perlu dilestarikan dan mempertahankannya. Esensi Tradisi yang merupakan kebiasaan -kebiasaan yang dilakukan sejak lama dan menjadi bagian dari kehidupan suatu kelompok masyarakat. Hal yang mendasar dari tradisi adalah adanya informasi yang diteruskan dari generasi ke generasi baik tertulis maupun lisan. Karena tanpa adanya hal tersebut, suatu tradisi dapat punah dan dalam tradisi juga terdapat upacara ritual yang diadakan secara berkesinambungan. Karena dijadikan acuan dalam bertingkah laku, maka tradisi cenderung menjadi kebudayaan dalam ruang lingkup yang lebih besar.

Selain merupakan cikal bakal kebudayaan Bali, mempertahankan untuk melanjutkan eksistensi dari tradisi tersebut merupakan wujud dari kepedulian atas kekayaan asli daerah. Sehingga mampu menunjukkan jati dirinya dalam memperoleh suatu keistimewaan dan sebagai identitas daerah. Kekhasannya dalam suatu tradisi merupakan suatu unsur yang terpenting dalam menentukan citra kualitas budaya. Kompleksitas keberadaan kesenian daerah dengan membangun fundamental masyarakatnya mampu 
menjadikan benteng pertahanan aktivitas sosial di masyarakat.

Khususnya masyarakat di Desa Adat Kedonganan, melaksanakan tradisi yang bernama Mebuug - Buugan dan dilaksanakan setiap pergantian tahun Çaka yakni pada hari raya ngembak geni. Bertepatan tahun 2017, merupakan pelaksanaan yang ketiga setelah direkontruksi kembali pada tahun 2015. Begitu luhurnya falsafah yang terkandung dalam tradisi Mebuug-Buugan, menjadikan masyarakat Desa Adat Kedonganan sangat antusias dalam pelaksanaan bahkan untuk menjaga tradisi asli Kedonganan ini. Tradisi Mebuug- buugan yang tergolong dalam upacara Bhuta Yadnya, sekaligus sebagai aktraksi kebudayaan, memiliki nilai-nilai agama yang terkandung didalamnya sebagai Tatwa, Etika, Upakara, Estetika, kebersamaan dan sosial budaya. Melalui pesan yang terdapat dalam tradisi MebuugBuugan tersebut, warga masyarakat khususnya Desa Adat Kedonganan begitu menghayati memaknai dan memahami isi yang terkandung didalamnya, sehingga tradisi tersebut senantiasa terpelihara dan dijaga dari kepunahan. Begitu pula sebagai generasi muda yang merupakan pewaris tradisi Mebuug-buugan, senantiasa dapat menyaksikan ,memelihara dan meneruskan pelaksanaan tradisi Mebuug-Buugan Desa Adat Kedonganan, Kecamatan Kuta, Kabupaten Badung.

Dengan latar belakang diatas, maka perlu untuk melakukan pengamatan secara lebih dekat sehingga mampu terserap norma-norma dan nilai agama yang terkandung didalamnya. Dalam penelitian ini untuk memberikan gambaran dan uraian tentang objek yang diteliti, maka jenis dan pendekatan penelitian sangat penting dalam penyusunan karya ilmiah, bertujuan untuk membatasi suatu kajian yang telah ditentukan sebelumnya. Jenis penelitian yang digunakan adalah penelitian kualitatif. Metode penelitian kualitatif adalah metode penelitian yang berlandaskan pada filsafat postpositivisme, digunakan untuk meneliti pada kondisi obyek yang alamiah, ( sebagai lawannya adalah eksperimen ) dimana peneliti adalah sebagai instrument kunci, pengambilan sampel sumber data dilakukan secara purposive dan snowball, teknik pengumpulan data dengan trianggulasi (gabungan), analisis data bersifat induktif/kualitatif, dan hasil penelitian kualitatif lebih ,menekankan makna dari pada generalisasi (Sugiyono, 2008: 15). Teori yang digunakan untuk penelitian ini adalah teori symbol, Teori religi dan Teori behavioristik. 


\section{PEMBAHASAN}

\subsection{Sejarah Desa Adat Kedonganan}

Menelusuri sejarah Desa Adat Kedonganan sungguh tidak mudah.Hingga kini, belum ditemukan sumber-sumber tekstual yang mengungkapkan jelas kapan Desa Kedonganan mulai berdiri dan mengapa Desa ini bernama Kedonganan.Kata Kedonganan berasal dari kata "donga" yang artinya tempat bagi para istri nelayan untuk meninjau para nelayan (suaminya) tatkala pergi melaut yang berada di pesisir pantai. Ada juga pendapat lain yang mengatakan kata kedonganan berasal dari kata 'kadung' dan 'aan' artinya daerah rendah yang terendam air karena secara geografis diapit oleh laut. Sesuai dalam Babad Bali dan Dharma Yatra Dhang Hyang Dwijendra dan Babad Arya yang sampai sekarang masih di Gedong Kirtya Singaraja, Desa Adat Kedonganan pada awalnya Kedongayan dan lama kelamaan berubah menjadi Kedonganan.

Kendati begitu, sejumlah babadmenyebutkan nama Kedongayan yang diduga sebagai nama awal Kedonganan. Seperti dikutip dalam Eka Ilikita Desa Adat Kedonganan, dalam lontarBabad Ularan disebutkan Kedongayan sebagai salah satu tempat yang disinggahi Ki Ularan.
Disebutkan, sekitar tahun 1246 Caka atau 1324 Masehi, Bali diperintah Sri Gajah Waktra atau Sri Tapa Ulung yang berkeraton di Bedahulu. Kala itu, Sri Gajah Waktra mengangkat sejumlah mentri sebagai Pengabih, yaitu Ki Ularan di Bali Selatan, Ki Tunjung Tutur di Tianyar, Ki Tunjung Biru Tenganan, Ki Kopang di Seraya, Ki Buwan di Batur, Ki Tambyak di jimbaran dan Ki Walung Singkal di Taro.

Ki Ularan Pernah menyinggahi sejumlah desa di pesisir selatan Bali seperti Tuban, Kelahan dan Kedongayan. Dalam masa invasi Gajah Mada ke Bali, nama Kedongayan juga turut disebut-sebut sebagai tempat pendaratan tentara Majapahit bersama Kuta Mimba, Kelahan dan Tuban.

Ini berarti, berdasarkan versi ini, nama Kedonganan sebelumnya adalah Kedongayan, paling tidak sampai pada zaman Bedahulu. Hanya, mengapa desa ini diberi nama Kedongayan masih sulit untuk dilacak. Versi lain menyebutkan hal yang berbeda. Dalam buku Monografi Desa Tuban tahun 1980 maupun Monografi Kelurahan Tuban tahun 1990 dulu kedonganan masih menjadi satu dengan Tuban disebutkan nama Kedonganan berasal dari kata gedong yang berarti 
'tempat bersujud','mengheningkan cipta'. Diceritakan setelah kalah dalam pertempuran di kerajaan Gelgel, I Gusti Ngurah Maruti pergi melarikan diri. Pertama-tama, sang patih yang kemudian karena memberontak berhasil menjadi penguasa di Gelgel selama lebih dari 30 tahun itu tiba di Kelan. Dari sini Sang Patih melanjutkan perjalanannya ke selatan.Di tempat inilah I Gusti Agung Maruti mengenang nasibnya, kekalahannya, swadharma-Nya dan mengheningkan sipta menunggalkan angga sarira, memuja kebesaran Ida Sang Hyang Widhi.Mengenang pentingnya arti tempat tersebut kemudian diberi namaGedongan.Lama-kelamaan berubah menjadi Kedonganan.

Untuk menentukan manakah versi yang benar, memang dibutuhkan penelitian yang lebih lanjut.Terlepas dari berbagai versi tersebut, kuat dugaan Desa Adat Kedonganan merupakan desa kuno.Hal ini terlihat dari adanya Pura Penataran.Biasanya, Pura Penataran hanya dimiliki desa-desa kuno, seperti Bayung Gede, Penglipuran dan desa-desa kuno lainnya.Akan tetapi, untuk sementara kedua versi ini diterima sebagai sebuah kekayaan sejarah Kedonganan. Tidak hanya Kedonganan yang memiliki ragam versi sejarah, banyak desa atau tempat lain juga mewarisi sejarah dengan berbagai macam versi.

Dari masa kemasa kini Kedongananjuga merupakan sebuah Desa Adat yang otonom. Secara kedinasan, Kedonganan juga merupakan sebuah wilayah dengan satu pemerintahan dinas kelurahan di wilayah Kecamatan Kuta, Kabupaten Badung. Kedonganan berbatasan dengan Desa Adat Kelan atau Kelurahan Tuban di utara, serta Desa Adat dan Kelurahan Jimbaran di selatan.Di barat dan timur Kedonganan di batasi oleh laut.

Desa Adat Kedonganan memiliki amongan (tanggung jawab) sejumlah Pura.Ada Pura Kahyangan Tiga yang meliputi PuraPusehDesa dan Pura Dalem. Selain Kahyangan Tiga ada juga terdapat sejumlah Pura lain yang juga dalam emongan desa adat, di antaranya Pura Penataran, Pura Segare, Pura Ratu Ayu, Pura Bale Agung, dan Pura Melanting. Di luar itu masih ada sejumlah pura yang memiliki pengamong dari kelompokkelompok warga.

\section{Letak Geografis Desa Adat Kedonganan \\ Desa Adat Kedonganan memiliki luas wilayah yang tidak begitu luas, lebih kurang sekitar $1 \mathrm{Km} 2$. Dari pusat kota}


propinsi bali berjarak30 $\mathrm{km}$ dan dari jarak pusat pemerintahan badung berjarak $45 \mathrm{~km}$.

Menurut data profil desa tahun 2018 adapun batas-batas wilayah Desa Adat Kedonganan adalah sebgaai berikut:

a. Sebelah Utara berbatasan dengan Desa Adat Kelan

b. Sebelah Timur berbatasan dengan hutan mangrove

c. Sebelah Selatan berbatasan dengan Desa Adat Jimbaran

d. Sebelah Barat berbatasan dengan pantai

Sarana dan prasarana yang menghubungkan Desa Adat Kedonganan dengan kota Kecamatan dan kota Kabupaten sampai ibu kota Provinsi sangat mendukung, ditambah dengan akses jalan raya yang sudah di aspal dengan baik serta sudah mendapat trotoarisasi. Pusat desa dapat ditempuh melalui satu jalur dari arah denpasar menuju keselatan melewati Desa AdatKuta menuju ke selatan melawati Desa Tuban keselatan melewati Desa Kelan keselatan dan tiba di Desa Kedonganan.

\section{Keadaan Demografis Desa Adat}

\section{Kedonganan}

Demografi adalah ilmu yang mempelajari tentang penduduk dalam suatu wilayah dengan faktor-faktor pengubahannya (moralitas, natalitas, migrasi dan distribusi). Secara umum demografi adalah ilmu yang mempelajari pesoalan dan keadaan-keadaan perubahan penduduk atau dengan kata lain segala hal yang berhubungan dengan komponenkomponen perubahan tersebut seperti kelahiran, kematian dan migrasi sehingga meghasilkan suatu keadaan dan komposisi penduduk menurut umur dan jenis kelamin tertentu. Penduduk merupakan sumber daya manusia sebagai salah satu faktor tertentu dalam pembangunan namun juga yang akan menikmati hasil pembangunan itu sendiri, dimana dalam hal ini kualitas serta kuantitas penduduk juga menjadi faktor penentu dalam pembangunan yang dilaksanakan.

Data mengenai keadaan demografis Desa Adat Kedonganan berasal dari data statistik Desa Adat Kedonganan yang di dukung dengan frofil desa yang dimiliki oleh Desa Adat Kedonganan tahun 2018.

\section{Sejarah dan Makna Mebuug-Buugan}

Pada era penjajahan jepang tahun 1942-1945, keberadaan tradisi mebuugbuugan sudah berakar dan manjadi permainan yang sangat ditunggu - tunggu di kalangan masyarakat kedonganan. Menurut salah satu informan yang bernama 
Ni Wayan Doglas, pada masa itu adalah Alm I Wayan Glibeg yang merupakan penggerak atau inisiator munculnya istilah mebuug-buugan. Aktivitas ini awalnya dilaksanakan bertepatan dengan hari raya nyepi atau tilem kesanga, karena menurut informan pada perayaan nyepi terdahulu diperbolehkan untuk melakukan aktivitas. Hanya saja tidak diperbolehkan mesuunan" atau memikul sesuatu benda di kepala. Oleh karenanya muncul beberapa gagasan dari salah satu kelompok yang diketuai oleh Alm I Wayan Glibeg yang akhirnya permaianan Mebuug-buugan ini selalu berjalan secara spontanitas. Pada masa kepimpinan Alm I Wayan Rempyeg (Kak Kleneng) menjabat sebagai Kelian Desa (Bendesa) tradisi mebuug buugan telah menjadi sebuah permainan dikalangan anak-anak dan masyarakat saat itu.

Berlanjut pada era Alm I Wayan Rempyeg (Kak Kleneng) menjadi Kepala Desa, salah satu informan kunci dan sekaligus sebagai pelaku I Made Gandil yang sempat bersekolah di SR/ KUTSU JUKLU KOGAKO, KUTA, juga merupakan generasi kedua setelah dipelopori oleh Alm I Wayan Glibeg. I made Gandil kelahiran 1923 ini, juga lebih dikenal dengan nama Pekak Okoh merupakan salah satu pionir munculnya beberapa aktivis kelompok masyarakat yang jaman tersebut di kedonganan dikenal dengan nama Funu Bongkol, dan Funu Tebe. Sehingga ketika I made Gandil menjabat menjadi kepala Desa Kedonganan Tradisi mebuug-buugan diteruskan oleh I Made Rugeh berasal dari banjar pasek kelahiran tahun 1946. Pada era I Made Rugeh terlibat sebagai pelaku dan inisiator saat itu sempat mengalami masa stagnan sehingga Pada tahun 1960 tradisi mebuugbuugan dimunculkan kembali oleh I Komang Rapeng. Ketika I Komang Rapeng sebagai penggerak atau pinpinan kelompok permainan mebuug-buugan, pelaksanaan dari tradisi mabuug - buugan dilaksanakan pada saat manis nyepi, yang dikarenakan adanya seruan dari parisada bahwasannya pada saat nyepi tidak diperkenankan melakukan aktivitas apapun. Letusan gunung agung pada tahun 1963, hingga pada tahun 1965 yaitu terjadinya Peristiwa G/30/ S PKI, yang pada saat itu terjadi penumpasan partai komunis Indonesia, momentum ini sekaligus menjadi saksi bisu tersimpannya permata budaya di desa adat kedonganan yaitu tradisi mebuug-buugan.

Secara etimologi bahasa mebuugbuugan berasal dari kata "Buug " yang berarti tanah / lumpur dan "bhu" yang artinya ada atau wujud, sehingga berafiliasi 
menjadi kata "Bhur" yang artiya Bumi, tanah atau pertiwi sehingga awalan memenjadi sebuah kata kerja atau aktivitas. Dapat diartikan mebuug-buugan berarti sebuah interaktivitas dengan menggunakan tanah/ lumpur ( buug) sebagai media.

Dalam lontar Siwa Sesa-cnmna, juga menyebutkan Lembu Nandini sebagai wahana Dewa Siwa, yang tidak lain sebagai lambang ibu pertiwi ( Bhur) dan lambang kesuburan. Dalam kontekstual makrokosmos ( Bhuwana Agung ) mebuugbuugan adalah bentuk ucapan syukur atas Kesuburan yang telah dilimpahkan pada bumi pertiwi ( Bhuwana Agung ) sebagai tempat manusia dan semua makhluk hidup ciptaan-Nya berkembang biak. Sangat jelas diungkapkan dalam tradisi mebuug-buugan ,hal ini dipertegas dengan lagu berikut:

'Mentul-menceng, mentul menceng

'Glendang-glendong, glendang glendong.'

Lirik lagu yang dinyanyikan selama perjalanan tradisi mebuug-buugan ini sangat singkat dan secara umum mewakili dari makna' Purusa dan Pradana" antara lingga dan yoni"
Sedangkan dari kontekstual mikrokosmos dari kata "Bhu" yang berarti ada atau wujud, merupakan perwujudan badan kasar manusia ( Bhuwana Alit) yang terbentuk dari kelima unsur Panca Maha Bhuta. Dalam Lontar Bhumi Kawulan / Bhumi Siwagama menguraikan; Karena kesalahan Dewi Uma, maka Bhatara Guru mengutuk-Nya dan turun ke dunia menjadi Panca Dhurga yaitu ; Sri Dhurga, Raji Dhurga, Suksmi Dhurga, Dhari Dhurga, dan Dewi Dhurga. Sri Dhurga beryoga menciptakan Kalika-Kaliki, Yaksa-Yaksi, Bhuta Dengen. Raji Dhurga beryoga minciptakan Jin-Setan, Bragala-Bregali, Bebai dan segala jenis penyakit. Dhari Dhurga beryoga menciptakan Sang Bhuta Kapiragan, Suksmi Dhurga beryoga menciptakan Kumala-Kumali ,Sweta dan lain-lain. Dewi Dhurga beryoga menciptakan Bhuta Jangitan, Bhuta Langkir, Lembu Kere, Lembu Truna, dan Bhuta Tiga Sakti. Melihat Uma menjadi Dhurga maka Bhatara Guru mengutuk diriNya sendiri menjadi Kala Rudra. Karena sentuhan Kala Rudra ini pada dewi Uma terciptalah Bhuta Kala yang memenuhi ruang waktu.

Melihat dari refrensi lontar Bhumi Kawulan / Bhumi Siwagama semua unsur baik makrokosmos (Bhuwana Agung ) 
maupun mikrokosmos ( Bhuwana Alit ) yang terbentuk dari unsure - unsure Panca Maha Bhuta, diliputi dan dipenuhi oleh kekuatan Bhuta Kala yang senantiasa memenuhi ruang dan waktu. Dalam hal ini manusia sebagai mahluk ciptaan Tuhan juga tidak terhindar dari kekuatan bhuta yang memenuhi ruang dan waktu tersebut. Oleh karena itu seyogyanya umat Hindu menetralisir hal-hal atau pun sifat - sifat buruk yang berasal dari sifat sifat Panca Maha Bhuta sebagai unsur pembentuk badan kasar. Dalam hal menetralisir kekuatan / sifat - sifat buruk pada diri manusia dapat dilaksanakan dengan melakukan tapa Brata Yoga Semadi.

Korelasi mebuug - buugan dengan pelaksanaan Tapa Brata Yoga Semadi dalam rangka menetralisir kekuatan Panca Maha Bhuta ( Nyomia Bhuta) sangat jelas terlihat dari rangkaian pelaksanaan prosesinya. Dimulai dari kegiatan upacara yang bertujuan untuk menetralisir keuatan bhuta pada makrokosmos dengan pelaksanaan upacara menghaturkan caru Tawur Kesanga yang dipusatkan pada catus pata sebagai stana sang hyang adikala. Sedangkan pada diri manusia ( mikrokosmos ), kekuatan bhuta dinetralisir dengan melaksnakan Catur Brata Penyepian yang pelaksanaannya bertepatan pada hari
Raya Nyepi. Pelaksanaan Catur Brata Penyepian meliputi Amati Geni, Amati Lelungaan, Amati karya, Amati Lelangunan. Dengan memaknai sebuah pengendalian diri / introspeksi diri ( Mulat Sarira ), kita diharapkan mampu mengendalikan segala bentuk kekuatan bhuta yang ada dalam diri manusia, sehingga kita bisa terbebaskan dari dosa atas pikiran, dosa atas perkataan dan dosa atas perbuatan kita.

Visualisasi dari belenggu kekuatan Bhuta dan keterbebasan kita dari kekuatan Bhuta itu sendiri diwujudkan dengan mebuug buugan. Dalam konteks mebuug-buugan manusia yang divisualisasikan dengan balutan gestur tanah / lumpur di maknai sebagai perwujudan Bhuta Kala atau kekotoran yang melekat dalam badan kasar manusia.Untuk dapat menghilangkan kekuatan bhuta dalam buana alit ( badan Kasar manusia), akan dimohonkan anugrah dari kekuatan laut (Segara) yang berfungsi sebagai kekuatan penyempurnaan (Pemarisudha) 


\section{Pelaksanaan Kegiatan}

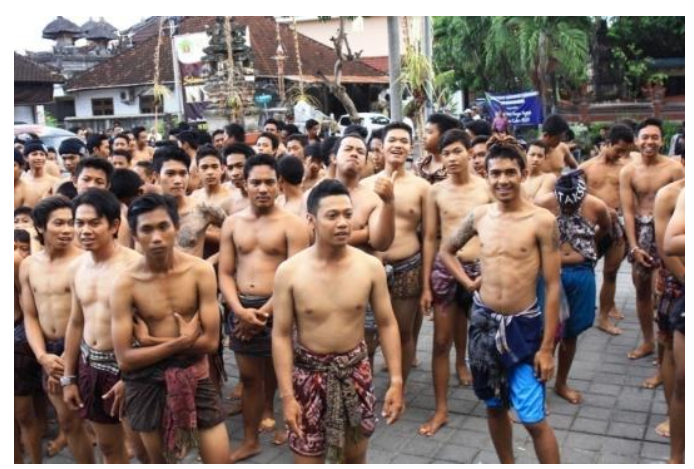

1. Tahapan kegiatan awal tradisi Mebuug Buugan, para pemuda dan masyarakat berkumpul di pelataran/ Jaba Pura Bale Agung Desa Adat Kedonganan dengan waktu yang telah ditentukan. Antusias semua lapisan masyarakat beserta pemuda berbondong - bondong penuh dengan kegembiraan dengan memakai kamben/ perlengkapannya masing- masing. Pada saat momentum ini, sangat terlihat keakraban para pemuda masing-masing banjar se-Desa Adat Kedonganan dengan harapan dan tujuan yang sama menyambut Tradisi Mebuug - Buugan. Terdapat beberapa hal yang wajib dilakukan dalam etika berbusana dalam tradisi Mebuug-Mebuugan, hal ini telah ditentukan kepada semua masyarakat agar menggunakan kamen "mebulet ginting".

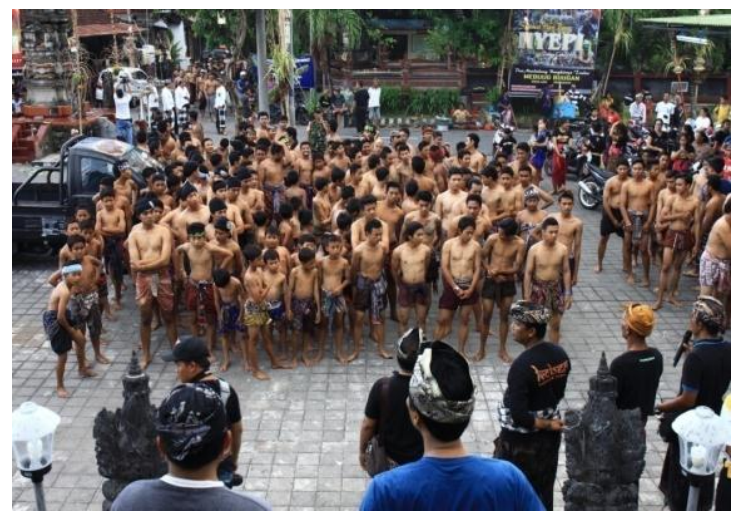

2. Setelah semua peserta Mebuug-buugan berkumpul, tahapan selanjutnya dilakukan pembekalan dari Prejuru Desa serta pihak keamanan agar berlangsungnya kegiatan tradisi mebuug-buugan berjalan sesuai rencana. Selain hal tersebut terdapat beberapa cacatan yang perlu untuk diketahui agar para peserta tidak melakukan arogansi dalam berlangsungnya tradisi yang adi luhung ini. Untuk mengantisipasi halhal yang tidak diinginkan pembekalan seperti ini sangat perlu dilaksanakan sebelum dimulai atau berjalannya para peserta Mebuug-Buugan.

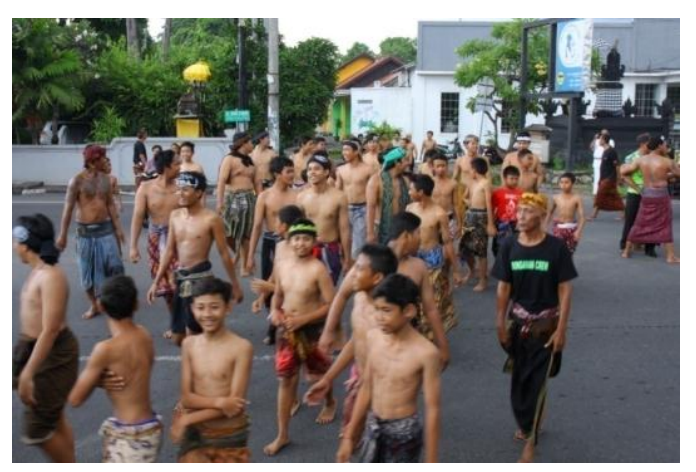

3. Para pemuda dan masyarakat peserta tradisi Mebuug - Buugan melakukan 
perjalanan dari titik lokasi berkumpul yakni di Pelataran Pura Bale Agung menuju ke Pantai timur Mangrove. Adapun rute yang dilalui adalah peserta bergerak ke selatan dari Pura Bale Agung menuju Jalan bantas Kangin, berikutnya dilanjutkan dengan menyebrang Jalan Bay Pass Ngurah Rai menuju ke Arah Timur yaitu Jalan Setra Ganda Mayu. Semangat masyrakat dan pemuda menempuh perjalanan kurang lebih 300 Meter menuju Mangrove tidak menyurutkan kegembiraan mereka. Tidak berselang beberapa menit semua masyarakat peserta Mebuug- Buugan tiba di lokasi Mangrove untuk melakukan aktivitasnya membaluti lumpur / buug ke badannya.

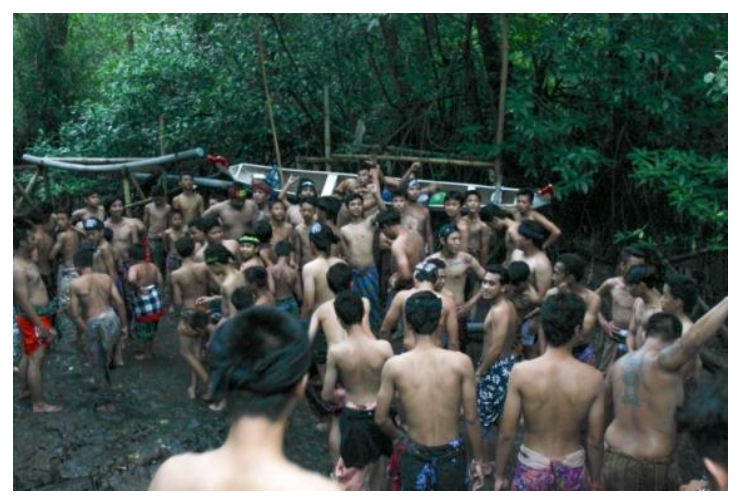

4. Setibanya di Mangrove / pantai timur Kedonganan, semua masyarakat, pemuda peserta Mebuug-Mebuugan turun menuju lokasi pengambilan buug/ lumpur. Perjalanan menuju lokasi pengambilan buug kurang lebih 50 meter ke arah timur yang harus dilewati turun sepanjang areal mangrove. Perlu diperhatikan sepanjang perjalanan di areal Mangrove tetap berhatihati mengingat medan yang berlumpur/tergenang air, tidak tertutup kemungkinan banyak yang harus diwaspadai ,seperti tritip/ akar pohon mangrove yang ujungnya runcing sangat banyak kita temui di areal ini. Selain tritip , ekosistem Mangrove tentunya tetap dijaga agar tidak terjadi sikap yang tidak harmonis dengan lingkungan sekitar. Dalam proses perjalanan ini, mengajarkan kita untuk bersinergi dengan lingkungan, alam sekitar khususnya di kawasan Mangrove agar senantiasa menjaga alam dan begitu mulianya nilai tradisi Mebuug-buugan untuk harmonis dengan alam.

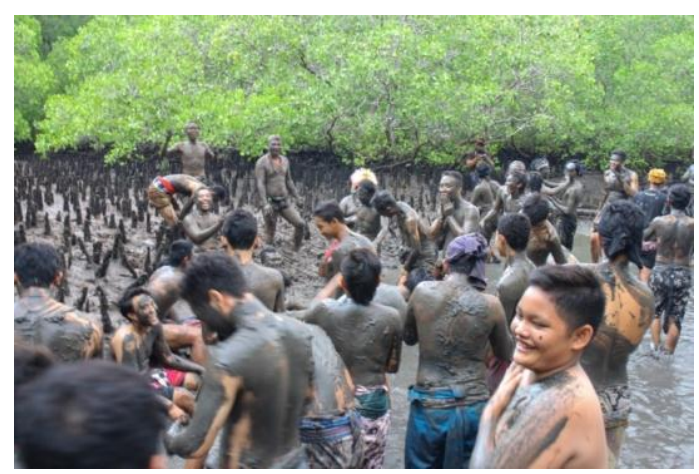

5. Di lokasi inilah semua masyarakat, pemuda para peserta Mebuug-Buugan menyampaikan ekspresinya untuk bersama sama melumpuri tubuhnya dengan buug/lumpur. Masyarakat kedonganan menyebutkan di lokasi ini sebagai Loloan 
dawal secara bahasa Indonesia bisa disebutkan akses jalan yang panjang menuju pantai timur. Hanya di lokasi ini bisa kita jumpai buug punglu/( lumpur yang tingkat kepadatannya menyerupai tanah liat). Buug yang telah diperoleh akan menjadikan para peserta begitu hiporianya saling melumpuri sesama temannya bahkan juga terjadi atraksi permainan lempar melempar lumpur. Akan tetapi hal tersebut hanyalah sebuah bagian dari aktraktifitas dari peserta Mebuug -Buugan yang notabene hanya dijadikan luapan ekspresi kegembiraan. Seusai semua peserta Mebuug-Buugan melumpuri tubuhnya dengan balutan buug, tiba saatnya jero Mangku memberikan percikan air suci dalam pemahamannya semua peserta Mebuug-Buugan sebagai wujud/ visualisasi bhuta melakukan perjalanan mengelilingi desa diberikan keselamatan dan tidak terjadi hal-hal yang tidak diinginkan.

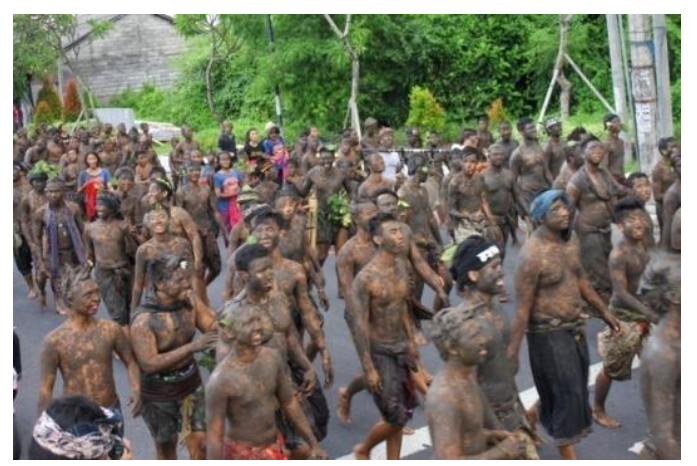

6. Setelah prosesi tersebut, dilanjutkan semua peserta Mebuug-Buugan melakukan perjalanan mengelilingi Desa. Adapun rute yang dilalui yakni kembali menuju arah barat Bay Pass Ngurah Rai Kedonganan menuju ke arah utara, sampai di pertigaan Jalan Toya ning menuju selatan dan ke barat menuju pantai Kedonganan. Dalam perjalanan yang panjang ini, semua peserta menyanyikan lagu yang khas dan hanya bisa kita jumpai di Tradisi Mebuug-Buugan ini. Mentul menceng" Mentul menceng"Glendang -glendong” GlendangGlendong” merupakan secarik lagu dengan beribu petuah dan makna yang terkandung didalamnya.

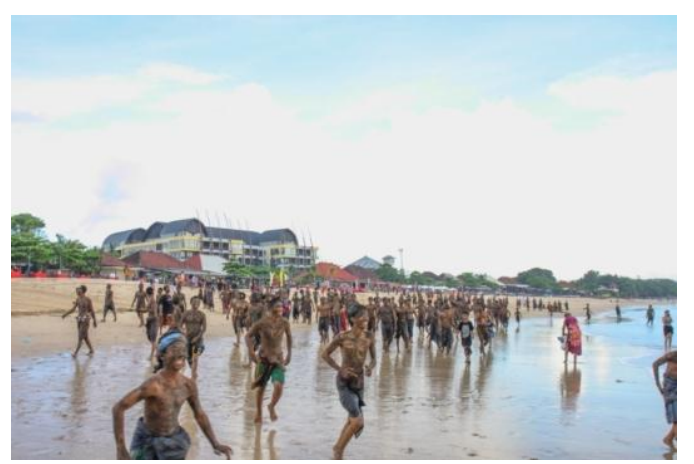

7. Setelah semua peserta Mebuug-Buugan tiba di pantai tepatnya di Pantai Pemlastian Desa Adat Kedonganan, pada saat ini semua melakukan pemandian bersama. Kegiatan mandi/melukat ini merupakan bagian akhir dari pelaksanaan kegiatan Tradisi MebuugBuugan. 
Latar Belakang Pelaksanaan Tradisi Mebuug-Buugan

\section{Alasan Theologi}

Theologi menurut (Yudha Triguna 2013 :12) dalam bahasa yunani disebut dengan Theologia, dari akar theos berarti Tuhan dan logos yang berarti wacana, ilmu. Secara keseluruhan Theologi berarti wacana atau ilmu tentang Tuhan. Tradisi Mebuug Buugan merupakan tradisi sakral yang dimiliki Desa Adat Kedonganan yang dapat dipertanggungjawabkan secara vertikal maupun horisontal. Secara vertikal keatas tarian ini merefleksikan hubungan kepercayaan kehadapan Ida Sang Hyang Widhi Wasa, dan secara horisontal kepada masyarakat sebagai wujud Asih, Punia dan Bhakti yang dilakukan dengan rangkaian upacara Yadnya secara bersama-sama, dari aspek Humanisme masyarakat Desa Adat Kedonganan mampu terjalinnya keharmonisan diantara masyarakat Desa Adat Kedonganan

\section{Alasan Mitologi \\ Mitologi berasal dari Bahasa Inggris "myth", artinya sembarang kisah atau cerita fiksi,sembarang orang atau sesuatu yang dianggap seolah-olah benar-benar ada. Sedangkan dalam Kamus Besar Bahasa Indonesia ( KBBI 2002:22 ), mitologi}

adalah ilmu tentang sastra yang mengandung konsepsi dan dongeng suci mengenai dewa dan makhlus halus dalam suatu kebudayaan. Tradisi Mebuug Buugan ini merupakan gambaran dari adanya keyakinan masyarakat terhadap unsur maha Buta yang menyelimuti kekotoran dalam badan kasar manusia. Masyarakat di Desa Adat Kedonganan meyakini tradisi ini dilaksanakan sebagai menetralisir kekuatan Bhuta yang masih melekat pada diri seusai melaksanakan catur Brata penyepian.

\begin{abstract}
Alasan Sosiologi
Sosiologi merupakan ilmu kemasyarakatan yang mempelajari hidup bersama dalam masyarakat, dan menyelidiki ikatan-ikatan antar manusia yang menguasai kehidupan (Idi, 2010 :7). Kebiasaankebiasaan yang dilakukan oleh masyarakat akan terus berkembang menjadi besar sehingga dapat lebih memiliki makna yang berarti. Sebuah tradisi sudah tentunya tidak dapat terlepas dari hubungan dan ikatan sosial dimana tempat tradisi tersebut berkembang. Tradisi ini dilaksanakan semata-mata tidak hanya untuk kepuasan pribadi, namun juga memiliki fungsi sosial untuk mengintensifkan solidaritas masyarakat.
\end{abstract}


Jadi dalam Tradisi Mebuug Buugan ini, interaksi sosial masyarakat sangatlah terasa selama rangkaian tradisi ini berlangsung. Dari persiapan sebelum dimulai hingga pelaksanaannya tidak terlepas dari interaksi masyarakat yang ada di Desa Adat Kedonganan.

\section{Alasan Filosofis}

Filosofis dalam bahasa yunani terdiri dari dua kata yaitu Philleins/Phillos yang berarti cinta dan Shopos/Shopia yang artinya kebijaksanaan, hikmah, ilmu dan kebenaran (Martiana, 2013 :47). Sejahteranya sebuah kehidupan sangat tergantung dari bagaimana sebuah keseimbangan sistem dapat berjalan sesuai dengan fungsinya masing-masing, keseimbangan dalam konsep Hindu dikenal dengan istilah Tri Hita Karana, hubungan yang harmonis antara manusia dengan Ida Sang Hyang Widhi Wasa tergambar dengan jelas ketika pelaksanaan pada upacara yang secara tidak langsung juga menjalin sebuah interaksi sosial antara masyarakat desa yang merupakan implementasi dari ajaran Tri Hita Karana. yang kedua adalah hubungan harmonis antara sesama manusia dan yang ketiga menjaga harmonisasi alam dalam wujud Bhaktinya melaksanakan Penyomya Bhuta. Dari ketiga keseimbangan tersebut akan mulai terciptanya sebuah kehidupan yang rukun dan harmonis antara sang pencipta, manusia dan alam.

\section{PENUTUP}

Berdasarkan pembahasan pada bab sebelumnya, maka dapat disimpulkan halhal sebagai berikut :

Bentuk dari Tradisi Mebuug-Buugan di Desa Adat Kedonganan, Kecamatan Kuta ,Kabupaten Badung ini adalah sebuah permainan dengan interaktivitas menggunakan media tanah lumbur atau Buug yang berasal dari Mangrove di kawasan Desa Adat Kedonganann. Penggunaan media tanah lumpur ini digunakan tidak sembarangan karena telah dipercaya sebagai sarana dalam tradisi Mebuug Buugan dan selain itu dari segi kesehatan telah dilakukan uji analitik dari Buug ini untuk meyakinkan tidak mengandung logam berat.

Melihat dari refrensi lontar Bhumi Kawulan / Bhumi Siwagama semua unsur baik makrokosmos ( Bhuwana Agung) maupun mikrokosmos (Bhuwana Alit) yang terbentuk dari unsure - unsure Panca Maha Bhuta, diliputi dan dipenuhi oleh kekuatan Bhuta Kala yang senantiasa memenuhi ruang dan waktu. Dalam hal ini 
manusia sebagai mahluk ciptaan Tuhan juga tidak terhindar dari kekuatan bhuta yang memenuhi ruang dan waktu tersebut. Oleh karena itu seyogyanya umat Hindu menetralisir hal-hal atau pun sifat - sifat buruk yang berasal dari sifat sifat Panca Maha Bhuta sebagai unsur pembentuk badan kasar. Dalam hal menetralisir kekuatan / sifat - sifat buruk pada diri manusia dapat dilaksanakan dengan melakukan tapa Brata Yoga Semadi.

Korelasi mebuug - buugan dengan pelaksanaan Tapa Brata Yoga Semadi dalam rangka menetralisir kekuatan Panca Maha Bhuta ( Nyomia Bhuta) sangat jelas terlihat dari rangkaian pelaksanaan prosesinya. Dimulai dari kegiatan upacara yang bertujuan untuk menetralisir keuatan bhuta pada makrokosmos dengan pelaksanaan upacara menghaturkan caru Tawur Kesanga yang dipusatkan pada catus pata sebagai stana sang hyang adikala. Sedangkan pada diri manusia ( mikrokosmos ), kekuatan bhuta dinetralisir dengan melaksnakan Catur Brata Penyepian yang pelaksanaannya bertepatan pada hari Raya Nyepi. Pelaksanaan Catur Brata Penyepian meliputi Amati Geni, Amati Lelungaan, Amati karya, Amati Lelangunan. Dengan memaknai sebuah pengendalian diri / introspeksi diri ( Mulat
Sarira), kita diharapkan mampu mengendalikan segala bentuk kekuatan bhuta yang ada dalam diri manusia, sehingga kita bisa terbebaskan dari dosa atas pikiran, dosa atas perkataan dan dosa atas perbuatan kita.

Visualisasi dari belenggu kekuatan Bhuta dan keterbebasan kita dari kekuatan Bhuta itu sendiri diwujudkan dengan mebuug - buugan. Dalam konteks mebuugbuugan manusia yang divisualisasikan dengan balutan gestur tanah / lumpur di maknai sebagai perwujudan Bhuta Kala atau kekotoran yang melekat dalam badan kasar manusia.Untuk dapat menghilangkan kekuatan bhuta dalam buana alit ( badan Kasar manusia), akan dimohonkan anugrah dari kekuatan laut (Segara) yang berfungsi sebagai kekuatan penyempurnaan (Pemarisudha)

\section{DAFTAR RUJUKAN}

Atmaja, I Made, dkk. 2010. Etika Hindu, Surabaya : Paramita Surabaya

Arkunto, Suharasini, 2000. Manejemen Penelitian, Jakarta : Rineka Cipta.

Arikunto, Suharsimi. 2006. ProsedurPenelitianSuatuPendekata nPraktik.Jakarta : PT. RinekaCipta 
Bandem, I Made dan deBoer, Fredrik Eugene.2004. Kaja dan Kelod. Jogjakarta : Badan Penerbit Jogjakarta.

Bungin, Burgan, 2001. Metodologi Penelitian Sosial. Surabaya "Airlangga University Pers

Dherana, TjokordaRaka. 1984. Hubungan Agama denganAdat., Denpasar : IHD

Dillistone, F.W.2006. The Power Of Symbol Daya Kekuatan Simbol. DiterjemahkanolehA.Widyamartaya. Yogyakarta:Kanisius

Dinas Pendidikan Dasar Propinsi Dati I Bai 1991. Kamus Bali-Indonesia, Denpasar.

Geriya, I Wayan. 2000. Transformasi kebudayaan Bali Memasuki Abad XXI.Surabaya;Paramita

Gulo W 2002. Metode Penelitian. Jakarta: Grsindo

Irawan, Prasetya. 2007. Longkadan Prosedur Penelitian. Jakarta : STIA-LAN Press.

Iqbal, Hasan. 2002. Metodologi Penelitian dan Aplikasinya. Jakarta: Ghalia Indonesia

Koentjaraningrat. 2002. Kebudayaan mentalitas dan pembangunan. Jakarta : PT GramediaPuatakaUtama

Koentjaraningrat. 2010. Sejarah Teori Antropologi .Jakarta :Universitas Indonesia
Kodiran. 1991. Konsep dan Pengembangan Kebudayaan Nasional. Yogyakarta: Fakultas Satra Universitas Gajah Mada

Kajeng, I Nyoman dkk. 2003 Sarasmuscaya, Jakarta:Pustaka Mitra Jaya

Margono, 1996. Metodologi Penelitian Pendidikan. Jakarta :Rineka Cipta

Moleong, Lexy J. 2001. Metodologi Penelitian Kualitatif. Bandung :Remaja Rosdakarya

Nawawi, Hadari. 1993. Metode penelitian bidag Sosial. Yogyakarta : Gajah Mada Universitas Press

Purwita, Ida BagusPutu. 1984. Desa Adat Dan Banjar di Bali, Percetakan Kawi Satra Denpasar

Pals, Daneil L. 2001. Seven Theories Of Religian. Jogyakarta. Qalam

Pudja, G. 1999. Bhagawad Gita. Surabaya; Paramita

Suprayogo, Imam \& Tobroni. 2003. Metodologi Penelitian SosialAgama. Bandung :Remaja Rosdakrya

Sanjaya, Putu. 2010. Acara Agama Hindu, Surabaya :Parmita

Sudarsana, Putu IB, 2001. Makna Upacara Bhuta Yadnya. Denpasar: Yayasan Dharma Arcaya, Percetakan Mandara sastra.

Suryani M.Si, Dra. 2011. Jenis dan hakekat Bhuta Yadnya pada masyarakat 
Hindu di bali. Denpasar:Uadayana University Press.

Sudharta, Tjok raid an I.B Oka punia Atmaja, 2001. Upakara Tentang Ajaran-ajaran Agama Hndu. Surabaya: Paramita

Yudabhakti, I Made Dan Watra, I Wayan.
2007. Filsafat Seni Sakral Dalam

Yudabhakti, I Made Dan Watra, I Wayan.
2007. Filsafat Seni Sakral Dalam
Kebudayaan

Hindu.

Surabaya:Parmita

Zamroni, 1992. Pengantar Pengembangan

Teori Sosial. Yogyakarta 